\title{
THE LONG-TERM IMPACTS AND THE EFFECTIVE TEACHING. A CASE STUDY IN CIVIL ENGINEERING AT THE TECHNICAL UNIVERSITY OF MADRID (SPAIN)
}

\author{
S. Alvarez-Gallego, R. Martinez-Marin, M. Marchamalo \\ Universidad Politécnica de Madrid (SPAIN)
}

\begin{abstract}
The current teaching methods are focused on results in the short term. However, learning must be focused on the acquisition of skills and abilities to be developed in the future. This case study has assessed the long-term impacts and the effective teaching at the subject of Topography and Cartography in the School of Civil Engineering (Polytechnic University of Madrid). To this end, a questionnaire with 10 questions was disseminated on two different populations. On the one hand, a total of 45 students who have just completed the course. On the other hand, the same questionnaire was conducted on a total of 166 students who took the subject for more than 2 years ago. The results from two years' experience (2016 and 2017) were compared. The students who just finished the course reached $12.7 \%$ higher results than those of the students who previously attended the course (from 75.7 to $85.3 \%$ of total correct answers). The study allows us to obtain information about which concepts and teaching activities have lasted over time and which have been easily forgotten.
\end{abstract}

Keywords: Cartography, Higher education, Innovation, Kahoot, Topography.

\section{INTRODUCTION}

Teaching must be measured by its quality. However, there is considerable debate about the best way to measure and improve teaching quality. Findings are frequently similar but almost as many are contradictory. This topic has been previously studied from different points of view. In one way there are studies that assess quality only based on students' satisfaction on the lecturer's performance [1]. On the other hand, there are studies show that effective teaching consists in the measurement of students' conceptions regarding specific dimensions such as achieved goals, long-term student development, teaching methods, relations with students, and assessment [2]. Therefore, it is important to understand how the different measures can influence the results.

Another topic of concern is how current teaching methods are focused on results in the short term. Almost all students are assessed annually despite the fact that their knowledge should be implemented during their professional life. Therefore, teaching must be focused on the acquisition of skills and abilities to be developed in the future. This point of view has been previously studied by Nasser-Abu [2]. Results from the mentioned study indicated that students perceived assessment as the most relevant teaching dimension and long-term development as the least important.

Finally, literature abounds with research on how different learning activities can be more effective than others. Multilevel analyses show that teacher's factors such as behavior are associated with student learning outcomes [3]. For example, it has been proved that teacher' significant life experiences and stories provide key resources for effective education programs [4]. Another example is gamification, a modern technique in education that involves the participation of the student as a gamer in a playful structure [5]. Implications for promoting a quality education shall be delivered from this type of analyses.

Tanking all this in mind, the aim of this paper is the assessment of how concepts and teaching activities can improve long-term teaching and therefore achieve a high-quality education.

\section{METHODOLOGY}

\subsection{Case study}

The case study is developed in the subject of Topography and Cartography that is being taught in the 4-years Bachelor degree in Civil Engineering at the School of Civil Engineering (Polytechnic University 
of Madrid, Spain). The subject of Topography and Cartography is taught in the second year. Therefore, it can be used to assess long-term impacts before students leave the university.

\subsection{Questionnaire}

Data were collected using a questionnaire. This questionnaire was designed to measure students' conceptions regarding 10 goals that should be achieved in the subject. As it is shown below, all questions were statements and students had to choose between correct or false. The complete questionnaire with the 10 mentioned questions is shown below:

1 The geoid is a geometric surface.

2 UTM projection is a reference system for geographical coordinates.

3 All maps are generated using a unique projection system and a unique reference system.

4 There are cartographic projections that do not present deformations.

5 The Cartesian coordinates of a vertex are assigned only according to a reference system

6 The geographical coordinates of a vertex are assigned according to a reference system

7 The representation of a surface in two dimensions requires the use of a projection system

8 The representation of the earth in two dimensions requires a reference system and a projection system

9 The maximum appreciable length on a map depends solely on the scale

10 The equidistance between contours depends solely on the scale of the map

The questionnaire was disseminated in 2016 and 2017 in two different populations. The first population conforms a total of 45 students who have just completed the subject (named as recently finished). The second population corresponds to a total of 166 students who took the subject for more than 2 years ago (named as 2 years after finishing). It should be noted that all students were taught the same education contains, so it was expected that both populations were achieving the same goals.

To get the survey done faster, the questionnaire was based on the Kahoot! platform. Kahoot! is a game-based platform that makes easy the real-time interaction between students and teachers. This platform uses internet connections and personal phones. It has been previously studied in different research papers. See as examples [5], [6] and [7]. All of them show positive feedbacks base on the experience.

\section{RESULTS}

\subsection{Results description}

The students who just finished the course reached $12.7 \%$ higher results than those of the students who previously attended the course two years ago (from 75.7 to $85.3 \%$ of total correct answers). The comparison of the two years' experience (2016 and 2017) provide similar results. The standard deviation between years was below 0.02 , in percentage terms.

Fig. 1 shows the differences between questions. It should be noted that results close to $50 \%$ represent the lowest values due to the fact that there were only two possible answers and it was mandatory to choose one. Otherwise, results close to $100 \%$ mean the best performance.

Results can be described in 3 groups. Firstly, half of the questions (Questions 1, 5, 6, 8 and 9) reached for the recently finished population better marks than the 2 years after finished population. Secondly, there were 4 questions (Questions 2, 4, 7, and 10) that reached similar results. Finally, it must be highlighted the high difference reached in Question 3 in which recently finished population reached worse results than 2 years after finished population. 


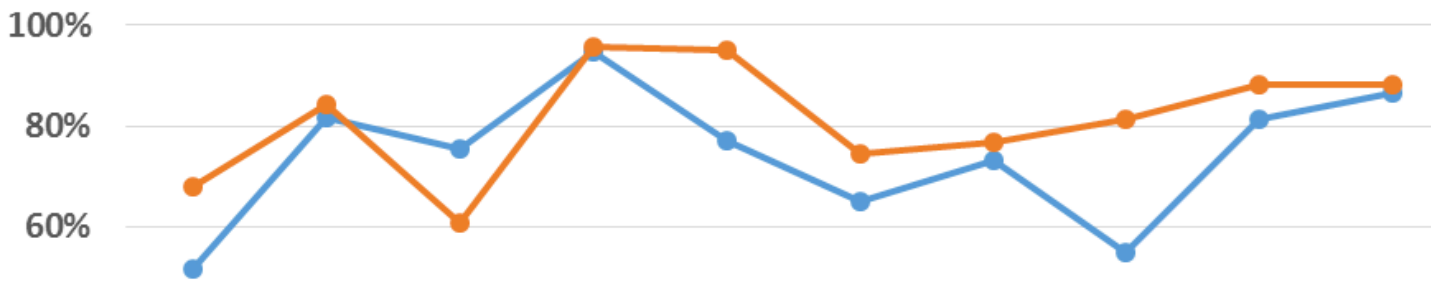

$40 \%$

$20 \%$

$0 \%$
Q1
Q2 Q3 Q4
Q5 Q6
Q7 $\quad$ Q8 $\quad$ Q9
Q10

Figure 1.Overall performace according to each question. Q: Question

\subsection{Discussion}

Results can be discussed according to the 3 groups stated in 3.1 Results description subsection. The first group shows what it could be expected. Students often try to do their best inside the year in which the subject is taught and assessed. After that, it is very common to forget and only remember what can be useful to them in order subjects. These questions were about two main topics: the geoid and the reference system. Both topics have a connection due to the reference system is the parametric simplification of the geoid.

The second group represents those who an effective teaching has been reached. These topics are related to the projection system. These results may have been reached due to two options. On the one hand, the taught concepts may have been used by another subject, and thus, they are inside what could be called as the core education. On the other hand, teaching activities developed in class may have helped the high performance. This assessment between options needs further studies because students have received classes from different teachers.

Finally, there is what could be called the exception to the rule. Results from question 3 are difficult to be interpreted in a comprehensive way. This is not what it could be expected so there must be an important influence from teaching activities, other subjects or the way the question was formulated. Authors consider this question was misunderstood by the finished population.

\section{CONCLUSIONS}

These experiences arouse relevant conclusions that should be taken into account to improve quality in the current teaching. Firstly, the teaching activities and concepts related to the geoid and the reference system must be improved to increase long-term impacts on the students. The success shown in topics related to projection system should be studied in order to assess influence from teaching activities or influence from other subjects. Finally, question 3 should be rephrased in other to assess if there has been a misunderstanding in its interpretation.

\section{ACKNOWLEDGMENTS}

This work has been supported by the Innovative Education Project "Geovoluntariado universitario: colaborando y aprendiendo con las organizaciones de ayuda humanitaria" (Ref IE1718.0411) funded by Universidad Politécnica de Madrid. 


\section{REFERENCES}

[1] M. Awang, B. Singh, and I. Dzulkarnain, "An Analysis of the Relationship between Effective Teaching and Effective Learning at UTP," Procedia - Soc. Behav. Sci., vol. 56, pp. 594-601, Oct. 2012.

[2] F. Nasser-Abu Alhija, "Teaching in higher education: Good teaching through students' lens," Stud. Educ. Eval., vol. 54, pp. 4-12, Sep. 2017.

[3] J. B. Azigwe, L. Kyriakides, A. Panayiotou, and B. P. M. Creemers, "The impact of effective teaching characteristics in promoting student achievement in Ghana," Int. J. Educ. Dev., vol. 51, pp. 51-61, Nov. 2016.

[4] S. Altan and J. F. Lane, "Teachers' narratives: A source for exploring the influences of teachers' significant life experiences on their dispositions and teaching practices," Teach. Teach. Educ., vol. 74, pp. 238-248, Aug. 2018.

[5] J. Sánchez-Martín, F. Cañada-Cañada, and M. A. Dávila-Acedo, "Just a game? Gamifying a general science class at university: Collaborative and competitive work implications," Think. Ski. Creat., vol. 26, pp. 51-59, Dec. 2017.

[6] T. J. Bristol, "Students, take out your phones," Teach. Learn. Nurs., vol. 13, no. 3, pp. 145-146, Jul. 2018.

[7] A. I. Wang, "The wear out effect of a game-based student response system," Comput. Educ., vol. 82, pp. 217-227, Mar. 2015. 